\title{
Influence of temperature on the larval development of Upogebia africana and U. capensis (Decapoda: Thalassinidae: Upogebiidae) in the laboratory
}

\author{
B. K. Newman ${ }^{1,3, *}$, I. Papadopoulos ${ }^{2}$, J. Vorsatz ${ }^{2}$, T. H. Wooldridge ${ }^{2}$ \\ ${ }^{1}$ Department of Zoology, University of Zululand, Private Bag 1001, Kwadlangezwa, 3886, South Africa \\ ${ }^{2}$ Department of Zoology, University of Port Elizabeth, PO Box 1600, Port Elizabeth, 6000, South Africa \\ ${ }^{3}$ Present address: Coastal and Marine Pollution, Natural Resources and the Environment, CSIR, PO Box 17001, \\ Congella 4013, Durban, South Africa
}

\begin{abstract}
The influence of constant temperature on the survival and development rate of Upogebia africana and $U$. capensis larvae was evaluated in the laboratory. $U$. africana larvae were reared at 7 constant temperatures between 12 and $29^{\circ} \mathrm{C}$, and $U$. capensis larvae at 6 temperatures between 11 and $26^{\circ} \mathrm{C}$. U. africana larvae were also exposed to fluctuating-temperature regimes, some of which simulated fluctuations in nearshore marine waters off the ovigerous female collection locality, to determine whether regression models describing the influence of constant temperature on the cumulative larval period can be extrapolated to predict the larval period under temperature conditions typical of those in the natural environment. Larval development in both species comprised 3 zoeal stages prior to a metamorphic moult to the Decapodid. A stage intermediate between the Zoea 3 and Decapodid was occasionally detected at high temperatures $\left(26\right.$ and $\left.29^{\circ} \mathrm{C}\right)$ for $U$. africana, and at $26^{\circ} \mathrm{C}$ for $U$. capensis. $U$. africana larvae completed development to the Decapodid at all temperatures, with highest survival at $23^{\circ} \mathrm{C}$. U. capensis larvae were unable to complete development to the Decapodid at $11^{\circ} \mathrm{C}$, showing highest survival at $17^{\circ} \mathrm{C}$. Stage-specific and cumulative duration of development in both species decreased sharply with increasing temperature until a threshold was reached, further increases in temperature having little additional effect on development rate. The temperature dependence of duration of development at temperatures below the threshold could be described by power functions for all zoeal stages as well as the cumulative larval period in both species. The thermal tolerance patterns for $U$. africana and $U$. capensis larvae agree well with geographical ranges of adults of both species along the southern African coastline, while differences in the optimal temperature for survival also agree with differences in their ranges. The effect of temperature fluctuations of the type simulated on $U$. africana larval development was expressed principally through variation in the rate of development, survival generally little affected, suggesting that $U$. africana larvae are physiologically well adapted to survive wide, rapid fluctuations in water temperature in the natural environment. Regression models describing the influence of constant temperature on the cumulative larval period appear to reliably predict the larval period under temperature conditions typical of those in the natural environment, with most reared larvae completing development at or shortly after the predicted period and with few exceptions within the predicted development period range.
\end{abstract}

KEY WORDS: Larval development $\cdot$ Temperature $\cdot$ Upogebia africana $\cdot$ Upogebia capensis

Resale or republication not permitted without written consent of the publisher

\section{INTRODUCTION}

Laboratory-based experimentation has identified temperature to be one of the most important environmental variables influencing the development of deca- pod crustacean larvae. Amongst other factors, survival, duration of development, metabolic rate and growth are modified by temperature (for a review of decapod larval ecology and biology see Anger 2001). One important objective for examining the influence of 
temperature on the development of decapod larvae in the laboratory is to infer, through the integration of these data with ambient water-temperature data, the larval period in the natural environment. Such data are sometimes incorporated into predictive models of larval transport and recruitment (see, for example, Johnson \& Hess 1990, Moloney et al. 1994). The predictive ability of these models obviously depends on the accuracy of the larval duration of development data used. However, laboratory-based larval rearing experiments are recognised as being highly artificial. From a temperature perspective, such experiments are almost exclusively conducted at constant temperatures, a highly unlikely scenario in the natural environment, and this raises questions about the reliability of extrapolating laboratory-derived larval-development data to variable field conditions in order to predict the larval period. Surprisingly, only limited attention has been directed at this problem.

Anger (1983) and Dawirs (1985) integrated duration of development data for Hyas araneus and Carcinus maenas larvae derived from constant-temperature experiments in the laboratory with regression models describing seasonal changes in water temperature for the Helgoland (North Sea) area to predict the larval period in the natural environment, and then they evaluated the usefulness of the models by rearing larvae in temperature regimes that simulated these changes. For larvae of both crabs, there was a good correspondence between observed and predicted periods. While the value of the data collected by Anger (1983) and Dawirs (1985) cannot be disputed, modelling fluctuations in seawater temperature through regression analysis has the effect of 'smoothing' between and within day fluctuations. Anger (1983) and Dawirs (1985) investigated only gradual, stepwise increases (implemented every few days) in water temperature on larval development in the laboratory. Provided that short-term fluctuations in temperature are small or there is a gradual (and generally unidirectional) change in ambient water temperature between seasons, and larval development periods are long, 'smoothing' of ambient temperature data through regression analysis should not seriously affect the outcome of predictions based on the integration of laboratory-derived data with mean water-temperature fluctuations. However, in temperate regions water temperature in the nearshore, where many decapod larvae complete development, can vary considerably from day to day in a manner that does not necessarily approximate the long-term daily mean. As an example of such variability, wind-driven upwelling along the south coast of South Africa can decrease nearshore water temperature by as much as $10^{\circ} \mathrm{C}$ within a few hours. However, upwelling is a stochastic feature of the nearshore oceanography in this area, dependant on wind direction and strength, and waters can remain at lowered temperatures, or return to pre-upwelling conditions, over a period of a few days (Schumann et al. 1982, 1988, Goschen \& Schumann 1995, Beckley 1988). Such fluctuation in water temperature undoubtedly influences the development of decapod larvae, and for species that have a short larval period may substantially affect the reliability of extrapolating laboratory-derived data to such variable field conditions.

Sulkin \& McKeen (1996) evaluated the influence of various water-temperature regimes on the larval development of Cancer magister, including regimes that simulated seasonal changes in water temperature as well as differences in water temperature between inland (Puget Sound) and offshore waters (central California, USA). These workers found distinct differences in larval development rates, which could be attributed to the higher water temperatures experienced in offshore compared with inland waters. There was little difference in survival between the experimental temperature regimes until the terminal zoeal stage, where larvae reared in temperature regimes simulating conditions in offshore waters suffered higher mortality compared to those reared under inland temperature conditions. Although growth (as measured by megalopal weight and carapace width and length) was affected by the different temperature regimes, these differences were not consistent with those observed in megalopae collected from the plankton of offshore and inland waters.

Several workers have examined the influence of short-term variability in water temperature on decapod larval development by exposing larvae to cyclic fluctuations in temperature (see, for example, Christiansen \& Costlow 1975, Rosenberg \& Costlow 1979, Sastry 1979). While the value of these data also cannot be disputed, cyclic fluctuations in temperature are also highly unlikely to occur in the natural environment.

The present study evaluated and compared the influence of temperature on the larval development of 2 upogebiid prawns, namely Upogebia africana and $U$. capensis. Larval responses to temperature were evaluated in terms of the geographical ranges of adults of both species along the southern African coastline. Regression models describing the influence of constant temperature on the cumulative larval period of $U$. africana were then used to predict the larval period under fluctuating-temperature regimes, some typical of those in the nearshore marine environment in one region of this prawns geographical range, and the predictive reliability of the models was then evaluated through laboratory experimentation.

Upogebia africana is a common and often extremely abundant resident of estuaries along the southern 
African coastline, with a wide (over 2000 $\mathrm{km}$ ) geographical range extending from the Olifants River estuary (South Africa) on the west coast to as far north as Inhambane (Mozambique) on the east coast (Fig. 1; Barnard 1950, Hill 1967, Day 1981). This range spans warm sub-tropical waters on the east coast, temperate waters on the south coast, and cold upwelled waters along the west coast (Christensen 1980, see Fig. 1). Although juveniles and adults are restricted to estuaries and sheltered embayments as a consequence of a requirement for muddy substrata in which to construct burrows (Wooldridge 1968), the larvae must obligatorily complete development in the marine environment (Wooldridge 1991, 1994, Wooldridge \& Loubser 1996). Newly released larvae leave the estuary for the marine environment almost immediately after hatching, where development comprising up to 4 zoeal stages prior to a metamorphic moult to the Decapodid (sensu Felder et al. 1985, equivalent of the megalopa in brachyuran crabs) is completed before recruitment to estuaries (Newman 2000).

Little is known about Upogebia capensis. Although the geographical range of this prawn is usually given as between Luderitz Bay and Mossel Bay (Fig. 1; see, for example, Day 1981, Branch et al. 1994), this is clearly incorrect, since populations have been recorded at several locations to the east of Mossel Bay, the eastern-most record being from the Kowie River estuary (Fig. 1; Hill 1971, B. Newman pers. obs.). Although adult $U$. capensis typically inhabits pebbleand shell-strewn sand between rocks in the marine intertidal and shallow subtidal, it has penetrated the extreme lower reaches of at least 3 estuaries where suitable substrata are present (Berg and Kowie River estuaries and Knysna Lagoon, Fig. 1; Kaljeta \& Hockey 1991, B. Newman pers. obs.). There have been no previous studies on the larval stages of this prawn.

\section{MATERIALS AND METHODS}

Collection and handling of gravid females and larvae. Ovigerous Upogebia africana and U. capensis with embryos in an advanced state of development (well-developed eyespots evident) were collected from the muddy intertidal zone of the lower reaches of the Swartkops River estuary and Knysna Lagoon respectively (Fig. 1). In the laboratory, the females were held in filtered $(0.5 \mu \mathrm{m})$, UV-irradiated seawater (salinity of

$35 \mathrm{ppt}$, hereafter referred to as culture water; salinity measured with Atago hand-held refractometer) at $20^{\circ} \mathrm{C}$ under an artificial 12:12 h light: dark (06:00 to 18:00 h) photoperiod until larvae hatched, which always occurred at night. All $U$. africana larvae hatched within $2 \mathrm{~d}$ of collection, while larvae from the $2 U$. capensis broods used hatched 4 and $9 \mathrm{~d}$ after collection.

Actively swimming larvae were collected at about 06:30 h the morning after hatching using a wide bore pipette and individually transferred to glass rearing vials filled with $15 \mathrm{ml}$ of culture water at $20^{\circ} \mathrm{C}$ and fed newly hatched ( $<8 \mathrm{~h}$ old) Artemia species nauplii (San Francisco Bay Brand ${ }^{\circledR}$ ). Daily, larvae were removed from the rearing vials and examined under a dissecting microscope to determine survival and development stage, and to examine for any obvious morphological defects. Larvae were then transferred to new rearing vials filled with culture water at the appropriate temperature, and fed. Daily analysis continued until all larvae had either metamorphosed to the Decapodid stage or died. Larvae were considered dead when opaque and/or no visible movement of internal or external structures and appendages could be detected under moderate magnification.

Constant-temperature experiments. After collection, larvae were acclimated to additional constant temperatures $\left(12,14,17,23,26\right.$ and $29^{\circ} \mathrm{C}$ for Upogebia 
africana and $11,14,17,23,26^{\circ} \mathrm{C}$ for $U$. capensis) at a rate of 2 to $3^{\circ} \mathrm{C} \mathrm{h}^{-1}$ by transferring rearing vials suspended in trays between water baths set at the appropriate temperature. Water temperature in the baths was measured every 2 to $3 \mathrm{~d}$ using a mercury thermometer, and deviated by a maximum of $0.4^{\circ} \mathrm{C}$ from the required temperature. After acclimation each temperature was represented by 20 to 24 individually reared larvae per brood. Larvae from 13 U. africana broods (initial $n=264$ ind. per temperature treatment, but see exceptions below) and from $2 U$. capensis broods (initial $n=44$ ind. per temperature treatment) were reared in this manner. Larvae from only 4 and 7 of the $13 U$. africana broods were reared at 12 and $29^{\circ} \mathrm{C}$ respectively, and at $11^{\circ} \mathrm{C}$ from only 1 of the $U$. capensis broods. Data from 1 experiment with $U$. africana at $14^{\circ} \mathrm{C}$ were accidentally lost.

Fluctuating-temperature experiments. These experiments were conducted about 2 yr after the constanttemperature experiments, using larvae hatched from 2 Upogebia africana broods that were also collected from the intertidal of the Swartkops River estuary. Ovigerous female maintenance and larval-rearing procedures were identical to those previously described, with the exception that in these experiments larvae were exposed to fluctuating temperatures and only 15 larvae from each brood were used per treatment. To evaluate whether development rates of larvae used in these experiments were consistent with those in previous experiments, larvae from each brood were reared at a constant (control) temperature of $20^{\circ} \mathrm{C}$. This temperature was selected as the control since ovigerous females were acclimated to and held at this condition until larvae hatched in the constant-temperature experiments. In other treatments larvae were exposed to fluctuating temperatures. In 2 treatments (Treatments 1 and 2) water temperature fluctuated in a cyclical manner between 16 and $24^{\circ} \mathrm{C}$, with larvae exposed to either 16 or $24^{\circ} \mathrm{C}$ on the first day (Fig. 2A). Two other treatments (Treatments 3 and 4) simulated temperature fluctuations in nearshore waters off the Swartkops River estuary mouth, using previously recorded daily (mid-morning) water-temperature measurements (Fig. 2A,B). In Treatment 3 water temperature varied by $7^{\circ} \mathrm{C}$ over the experimental period with a maximum difference between successive days of $5^{\circ} \mathrm{C}$, and in Treatment 4 by $6^{\circ} \mathrm{C}$ over the experimental period with a maximum difference between successive days of $6^{\circ} \mathrm{C}$. These wide fluctuations are associated with winddriven upwelling events, a fairly common feature of the nearshore oceanography during summer off the gravid female collection locality.

Originally it was anticipated that larvae from 3 broods hatched on the same date would be used for experimental purposes. The hatching date of Upoge-


Fig 2. Daily temperature regimes for Treatments 1 to 4 in fluctuating-temperature experiments

bia africana larvae is generally easily determined by visual examination of brood developmental status and larvae from several broods can thus usually be predicted to hatch at the same time. However, only 2 of the 5 broods hatched as predicted, and then only on successive nights ( 1 and $2 \mathrm{~d}$ after collection). The date of first exposure of larvae to the experimental treatments was consequently on successive days. Larvae from the first brood (Brood 1) to hatch were exposed to experimental temperatures indicated in Fig. $2 \mathrm{~A}, \mathrm{~B}$, and 
those from the second brood (Brood 2) to temperatures indicated in Fig. 2A,C.

Statistical analysis. Constant-temperature experiments: Data analysis followed standard procedures as described by Sokal \& Rohlf (1981) and Zar (1996), with inferences at the $\alpha=0.05$ level. For Upogebia africana, only duration of development data for larvae that completed development to the Decapodid were subjected to statistical analysis. In contrast, duration of development data for all $U$. capensis larvae were subjected to statistical analysis, due to smaller sample sizes. In both species an abnormal developmental stage was detected (see 'Results'), and data for these larvae were censored prior to statistical analysis. Duration of development data, and for $U$. africana also survival data, are presented as the arithmetic mean $\pm 1 \mathrm{SD}$.

Although contingency table analysis (G-test for homogeneity) indicated that stage-specific and cumulative survival differed significantly between larvae from the various Upogebia africana broods used at any single temperature, these differences were not only rare but showed no consistent relationship to zoeal stage or to brood hatching data (season). These differences were consequently attributed to natural variability between broods rather than to stage-specific susceptibility to temperature or to seasonal effects, and the survival data were thus pooled by temperature treatment for further analysis. Similarly for $U$. capensis, significant differences in survival of larvae from the 2 broods used at any single temperature showed no specific trend related to zoeal stage, and the data were thus also pooled by temperature treatment for further analysis.

The influence of temperature on Upogebia africana larval survival was evaluated by subjecting data to a 1way ANOVA (after proportions arc-sine transformed), followed where appropriate by a Tukey multiplecomparison test. Since U. capensis larvae originated from only 2 broods, comparison of survival between temperature treatments was performed using contingency tables, following a stepwise test procedure to identify homogenous groups (G-test for homogeneity; see Sokal \& Rohlf 1981, p. 728).

Distributions in the duration of development data sets for both species frequently deviated from normality (Kolgomorov-Smirnov test), and in many instances variances were also unequal (Bartlett's test). Data transformation (log and ln) frequently failed to approximate either data normality or variance homogeneity. Despite these violations of parametric test assumptions, untransformed duration of development data were analysed using more robust parametric rather than non-parametric statistical procedures. One-way ANOVA, followed where appropriate by a Tukey multiple-comparison test, was used to compare stage- specific and cumulative duration of development between the various broods of Upogebia africana at each temperature treatment, while $t$-tests were used for this purpose for $U$. capensis. For both species duration of development did not differ significantly between the various broods at any single temperature treatment, and data were consequently pooled by temperature treatment for further analyses. To determine whether temperature significantly influenced development rate, stage-specific and cumulative duration of development were compared between temperature treatments using 1-way ANOVA, followed where appropriate by a Tukey multiple-comparison test. One-way ANOVA was also used to compare duration of development periods between successive zoeal stages of each species at each temperature, and $t$-tests to compare duration of development periods for the same larval stage between the species at each temperature.

Quantitative relationships between stage-specific and cumulative duration of development and temperature were described by means of non-linear (power function) regression. Slopes of regressions were tested for significant differences from zero with $t$-tests, after linearisation by log transformation of both independent and dependent variables. Equality of regression slopes and intercepts was analysed using a procedure equivalent to ANCOVA, followed where appropriate by a Tukey test to identify regressions with dissimilar slopes.

Fluctuating-temperature experiments: Predicted larval durations in the fluctuating-temperature treatments were calculated as follows: (1) For each temperature to which larvae were exposed in the fluctuating-temperature treatments, the mean cumulative duration of development was determined from a regression describing the temperature dependence of mean cumulative duration of development. (2) The data were then divided into one to determine the instantaneous (daily) fraction of the mean cumulative duration of development at this temperature. (3) The instantaneous development fractions were then integrated with the fluctuating-temperature regimes and the fractions summed-when the summed value equalled one, completed (predicted) development to, the Decapodid was assumed. Calculations were performed to predict the mean, shortest and longest duration of development. To determine the shortest and longest durations of development, regressions were fitted to the fastest- and slowest-developing larvae in each constant-temperature treatment between 12 and $26^{\circ} \mathrm{C}$. These data were then used to determine relevant development durations in the same manner described for calculating the predicted mean larval duration. 
Duration of development data are presented as the arithmetic mean \pm SD. Due to differences in the hatching dates of the broods, data are only directly comparable between larvae used in the controls and in Treatments 1 and 2. Comparison of survival data was performed using contingency tables (G-test for homogeneity), using a stepwise procedure to identify homogenous groups. As was the situation for the constant-temperature experiments, duration of de- velopment data frequently deviated from normality (Kolgomorov-Smirnov test) and variances were often unequal (Bartlett's test). However, more robust parametric rather than non-parametric tests were used to compare mean cumulative duration of development between the broods, using either $t$-tests for pairwise comparisons or 1-way ANOVA followed where appropriate by a Tukey multiple-comparison test for multiple comparisons.

\section{Upogebia africana}

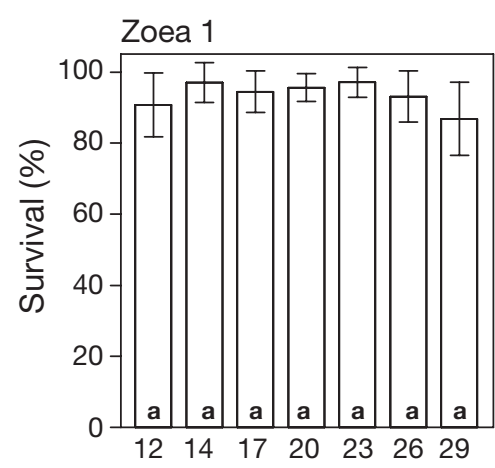

Zoea 2



Zoea 3

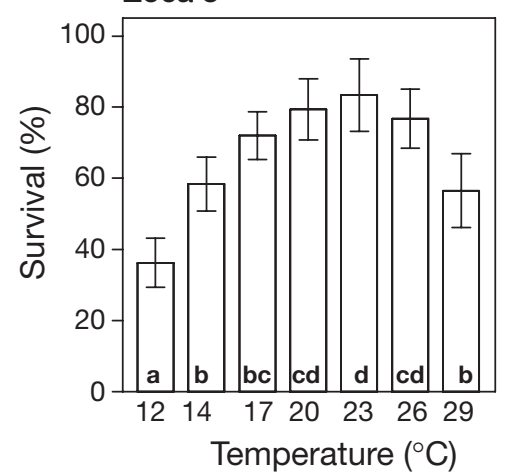

Upogebia capensis

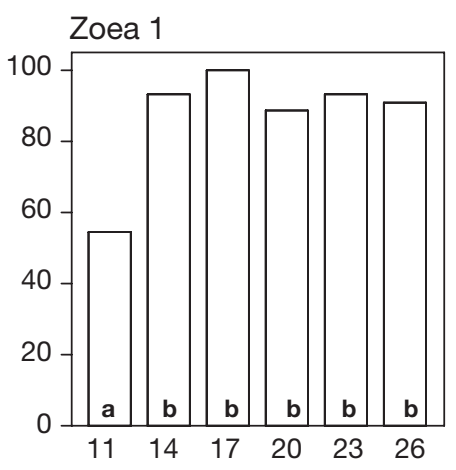

Zoea 2

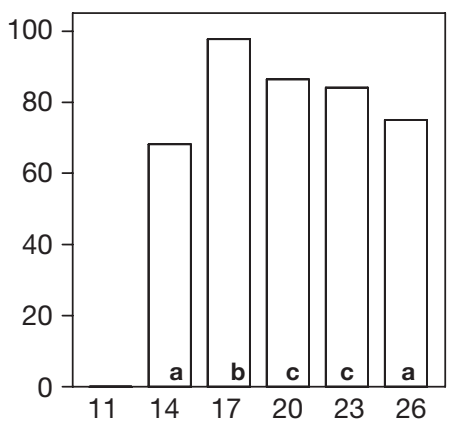

Zoea 3

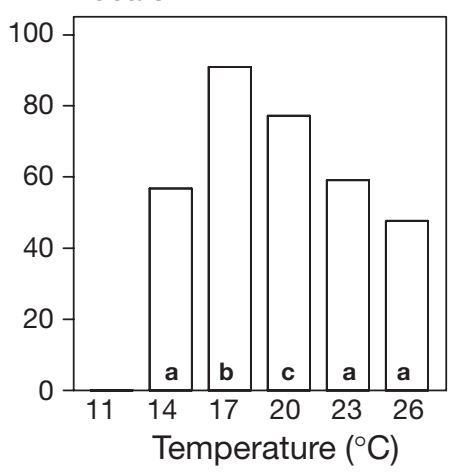

Fig. 3. Upogebia africana and $U$. capensis. Cumulative survival (mean $\pm \mathrm{SD}$ ) for successive zoeal stages of $U$. africana (left) and $U$. capensis (right) as a function of temperature. Different letters indicate statistically significant differences $(p<0.05)$ in mean survival between temperatures (based on 1-way ANOVA followed by a Tukey multiple-comparison test to determine homogenous groups for $U$. africana or a $G$-test for homogeneity for $U$. capensis)

\section{RESULTS}

\section{Constant-temperature experiments}

\section{Developmental stages}

The larval sequence in both species comprised 3 actively swimming zoeal stages, followed by a metamorphic moult to the Decapodid. A stage exhibiting various combinations of morphological characters typical of both the Zoea 3 and Decapodid (hereafter referred to as intermediate larvae) was detected on 13 occasions from 3 broods of Upogebia africana reared at 26 and $29^{\circ} \mathrm{C}$ and on 7 occasions from both broods of $U$. capensis reared at $26^{\circ} \mathrm{C}$. Intermediate larvae from both species were short-lived, with a maximum survival period of $2 \mathrm{~d}$ but usually less than $24 \mathrm{~h}$.

\section{Survival}

Upogebia africana larvae completed development to the Decapodid at all temperatures (Fig. 3). U. capensis larvae were unable to complete development to the Decapodid at $11^{\circ} \mathrm{C}$ (Fig. 3), all larvae that survived the Zoea 1 dying soon after moulting to the Zoea 2. In both species survival of the Zoea 1 was $>90 \%$ at most temperatures, and with the exception of $U$. capensis larvae at $11^{\circ} \mathrm{C}$ was not significantly influenced by temperature (Tables 1 \& 2, Fig. 3). Temperature exerted a greater influence on the survival of later larval stages in both species, particularly at the extreme temperatures examined (Fig. 3). Although cumulative survival to the Decapodid in U. africana was highest at $23^{\circ} \mathrm{C}$, there was no significant difference in survival over the range 20 to $26^{\circ} \mathrm{C}$. Survival at these temperatures was significantly higher compared with that 
Table 1. Upogebia africana. Results of 1-way ANOVA comparing cumulative survival (after proportions arc-sine transformed) for successive zoeal stages between temperatures (see also Fig. 3). dff, MSf, dfe, MSe: degrees of freedom and mean squares of factors and errors respectively; p: probability of rejecting a correct null hypothesis

\begin{tabular}{|cccccrr|}
\hline Stage & dff & MSf & dfe & MSe & $F$ & $p$ \\
\hline Zoea 1 & 6 & 0.091 & 68 & 0.056 & 1.63 & 0.151 \\
Zoea 2 & 6 & 0.474 & 68 & 0.036 & 13.04 & $<0.001$ \\
Zoea 3 & 6 & 0.390 & 68 & 0.023 & 16.99 & $<0.001$ \\
\hline
\end{tabular}

at 17 and $29^{\circ} \mathrm{C}$, survival at the latter temperatures in turn significantly higher compared with $12^{\circ} \mathrm{C}$ (Fig. 3). $U$. capensis larvae exhibited a preference for cooler temperatures, with cumulative survival to the Decapodid at $17^{\circ} \mathrm{C}$ significantly higher compared with the remaining temperatures. Survival at $20^{\circ} \mathrm{C}$ was in turn significantly higher compared with 14,23 and $26^{\circ} \mathrm{C}$, between which there was no significant difference (Fig. 3).
Table 2. Upogebia capensis. Results of G-tests for homogeneity comparing cumulative survival for successive zoeal stages between temperatures (see also Fig. 3). Abbreviations as in Table 1

\begin{tabular}{lccl|}
\hline Stage & df & $G$ & \multicolumn{1}{c|}{$\mathrm{p}$} \\
\hline Zoea 1 & 5 & 91.61 & $<0.001$ \\
Zoea 2 & 4 & 17.44 & $<0.01$ \\
Zoea 3 & 4 & 25.98 & $<0.001$ \\
\hline
\end{tabular}

below the threshold could be described by statistically highly significant power-model regressions for each zoeal stage as well as the cumulative larval period (Fig. 4). Slopes of regressions fitted to the Zoea 1 and 2 data were statistically similar $\left(F_{2,1460}=0.0869, \mathrm{p}=\right.$ 0.7862), but significantly shallower compared with that for the Zoea 3 (Zoea 1 versus Zoea 3: $F_{2,1460}=$ 15.161, $\mathrm{p}<0.0001$; Zoea 2 versus Zoea 3: $F_{2,1460}=$ 21.134, $\mathrm{p}<0.0001)$.

\section{Duration of development}

In both species the mean duration of development for each zoeal stage, and consequently also the mean cumulative duration of development, decreased sharply with increasing temperature until a threshold temperature was reached, after which duration either remained constant, more or less constant, or increased with further increases in temperature. In Upogebia africana the threshold temperature was $20^{\circ} \mathrm{C}$ for the Zoea 1 and $26^{\circ} \mathrm{C}$ for the Zoea 2 and 3 (Fig. 4). Each incremental increase in temperature between $12^{\circ} \mathrm{C}$ and the threshold temperatures resulted in a highly significant decrease in duration of development (Table 3, Fig. 4). For the Zoea 1, duration of development at temperatures between 20 and $29^{\circ} \mathrm{C}$ was constant at $2 \mathrm{~d}$. For the Zoea 2 , mean duration of development decreased until $26^{\circ} \mathrm{C}$, and then lengthened significantly at $29^{\circ} \mathrm{C}$ (albeit only marginally in absolute terms; $1.86 \pm 0.35 \mathrm{~d}$ versus $2.03 \pm$ $0.17 \mathrm{~d}$ respectively; Fig. 4). For the Zoea 3, mean duration of development at $29^{\circ} \mathrm{C}$ was marginally shorter compared with $26^{\circ} \mathrm{C}$, but this difference was not significant (Fig. 4). Although the mean cumulative duration of development at $29^{\circ} \mathrm{C}$ was longer compared with $26^{\circ} \mathrm{C}$, this difference was also not significant. The temperature dependence of duration of development at temperatures

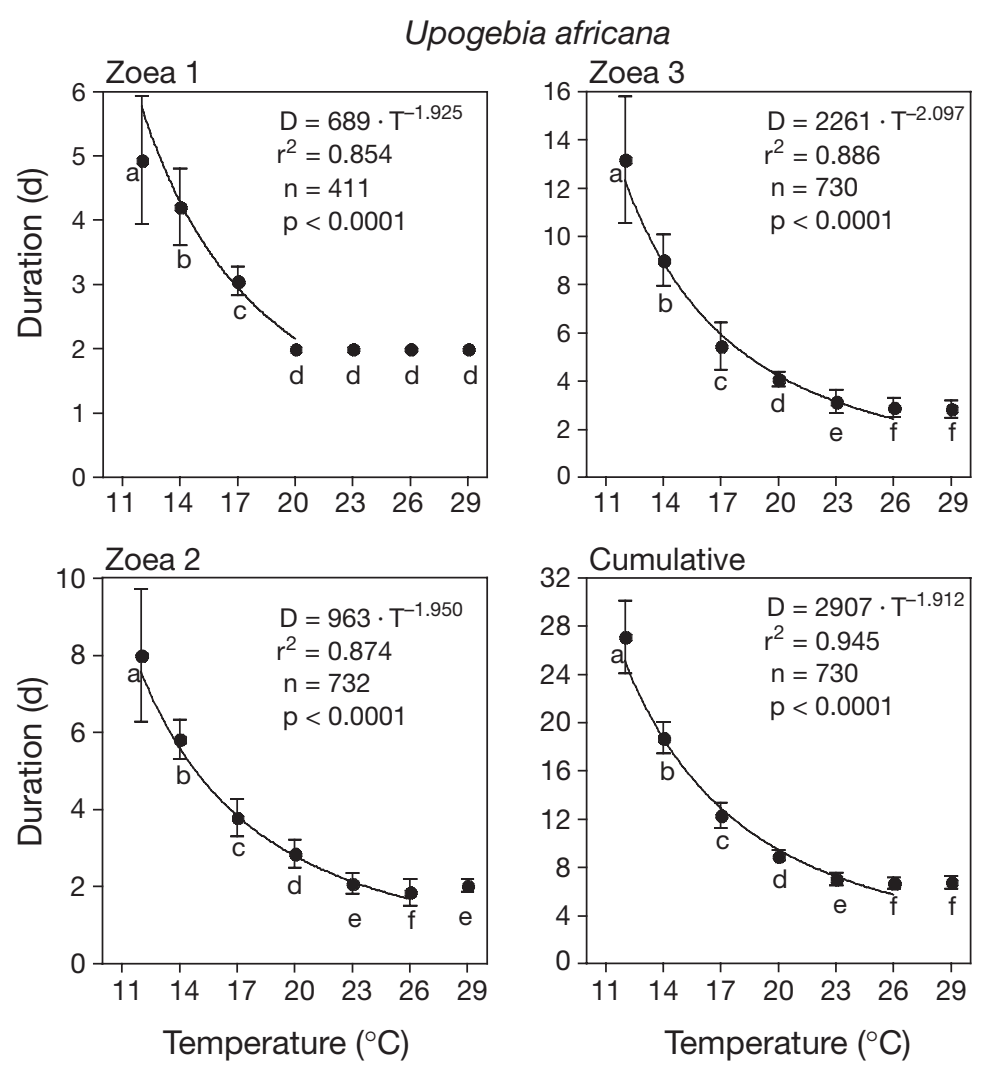

Fig. 4. Upogebia africana. Effect of temperature $(T)$ on duration of development $(D$, mean $\pm \mathrm{SD})$ in successive larval stages and for cumulative larval development. Regressions fitted to temperatures less than or equal to threshold temperature (see text for further details) given with fitted parameters, coefficients of determination $\left(\mathrm{r}^{2}\right)$, sample size (n) and significance level (p). Other statistics as in Fig. 3 (except that in all cases where letters are different $p<0.001$ ) 
Table 3. Upogebia africana. Results of 1-way ANOVA comparing mean duration of development for successive zoeal stages and the cumulative larval period between temperatures (see also Fig. 4). Abbreviations as in Table 1

\begin{tabular}{|lcccccc|}
\hline Stage & dff & MSf & dfe & MSe & $F$ & $p$ \\
\hline Zoea 1 & 6 & 111.611 & 792 & 0.071 & 1569.48 & $<0.001$ \\
Zoea 2 & 6 & 259.859 & 792 & 0.197 & 1320.83 & $<0.001$ \\
Zoea 3 & 6 & 705.709 & 792 & 0.546 & 1293.30 & $<0.001$ \\
Cumulative & 6 & 2775.2 & 792 & 0.760 & 3650.62 & $<0.001$ \\
\hline
\end{tabular}

Mean duration of development of successive zoeal stages of Upogebia africana showed an interesting trend. At each temperature between 12 and $20^{\circ} \mathrm{C}$ the Zoea 1 always had the shortest duration and the Zoea 3 the longest, with differences in mean duration between the different zoeal stages highly significant (Table 4, Fig. 5). At higher temperatures, while the Zoea 3 still had statistically the longest mean duration of development, the mean duration of the Zoea 1 and 2 were statistically similar at 23 and $29^{\circ} \mathrm{C}$, but at $26^{\circ} \mathrm{C}$ the Zoea 2 had a significantly shorter mean duration compared with the Zoea 1. However, this difference at $26^{\circ} \mathrm{C}$ was small, the Zoea 1 completing development in $2.0 \pm 0.00 \mathrm{~d}$ compared to $1.86 \pm 0.35 \mathrm{~d}$ for the Zoea 2 .

Trends in stage-specific and cumulative duration of development for Upogebia capensis were generally similar to those for $U$. africana larvae. In the Zoea 1, each incremental increase in temperature between 11 and $20^{\circ} \mathrm{C}$ resulted in a highly significant decrease in the mean duration of development (Table 5, Fig. 6). All but 1 larva completed development in $2 \mathrm{~d}$ at temperatures between 20 and $26^{\circ} \mathrm{C}$. In the Zoea 2, mean duration of development also decreased significantly with each incremental increase in temperature between 14
Table 4. Upogebia africana. Results of 1-way ANOVA comparing mean duration of development between zoeal stages at each rearing temperature (Temp., see also Fig. 5). Abbreviations as in Table 1

\begin{tabular}{|lccrlrc|}
\hline Temp. & dff & MSf & dfe & MSe & \multicolumn{1}{c|}{$F$} & $\mathrm{p}$ \\
\hline $12^{\circ} \mathrm{C}$ & 2 & 272.271 & 45 & 3.631 & 74.99 & $<0.001$ \\
$14^{\circ} \mathrm{C}$ & 2 & 582.872 & 294 & 0.578 & 1009.11 & $<0.001$ \\
$17^{\circ} \mathrm{C}$ & 2 & 205.247 & 402 & 0.414 & 495.98 & $<0.001$ \\
$20^{\circ} \mathrm{C}$ & 2 & 176.064 & 480 & 0.0785 & 2243.77 & $<0.001$ \\
$23^{\circ} \mathrm{C}$ & 2 & 80.978 & 495 & 0.0987 & 820.46 & $<0.001$ \\
$26^{\circ} \mathrm{C}$ & 2 & 50.467 & 462 & 0.0901 & 560.29 & $<0.001$ \\
$29^{\circ} \mathrm{C}$ & 2 & 11.96 & 198 & 0.084 & 142.42 & $<0.001$ \\
\hline
\end{tabular}

and $20^{\circ} \mathrm{C}$, remained more or less constant between 20 and $23^{\circ} \mathrm{C}$ (this difference was not significant), and then shortened significantly at $26^{\circ} \mathrm{C}$ (Table 5, Fig. 6). Mean duration of development of the Zoea 3 decreased significantly with increasing temperature between 14 and $23^{\circ} \mathrm{C}$, and then increased between 23 and $26^{\circ} \mathrm{C}$ (this difference not significant, Fig.6). Mean cumulative duration of development decreased significantly with each incremental increase in temperature, although the difference between 26 and $29^{\circ} \mathrm{C}$ was small $(6.84 \pm$ $0.37 \mathrm{~d}$ versus $6.24 \pm 0.44 \mathrm{~d}$ respectively). As was the situation for $U$. africana larvae, the temperature dependence of $U$. capensis larval duration of development could be described by statistically highly significant power-model regressions at temperatures below the threshold (Fig. 6). Although a power-model regression fitted to data for the Zoea 2 over the entire temperature range provided a statistically highly significant regression with a high coefficient of determination, the trend in duration of development over this temperature range was inconsistent with that for the Zoea 3 as well as for the cumulative larval period. Only Zoea 2 data
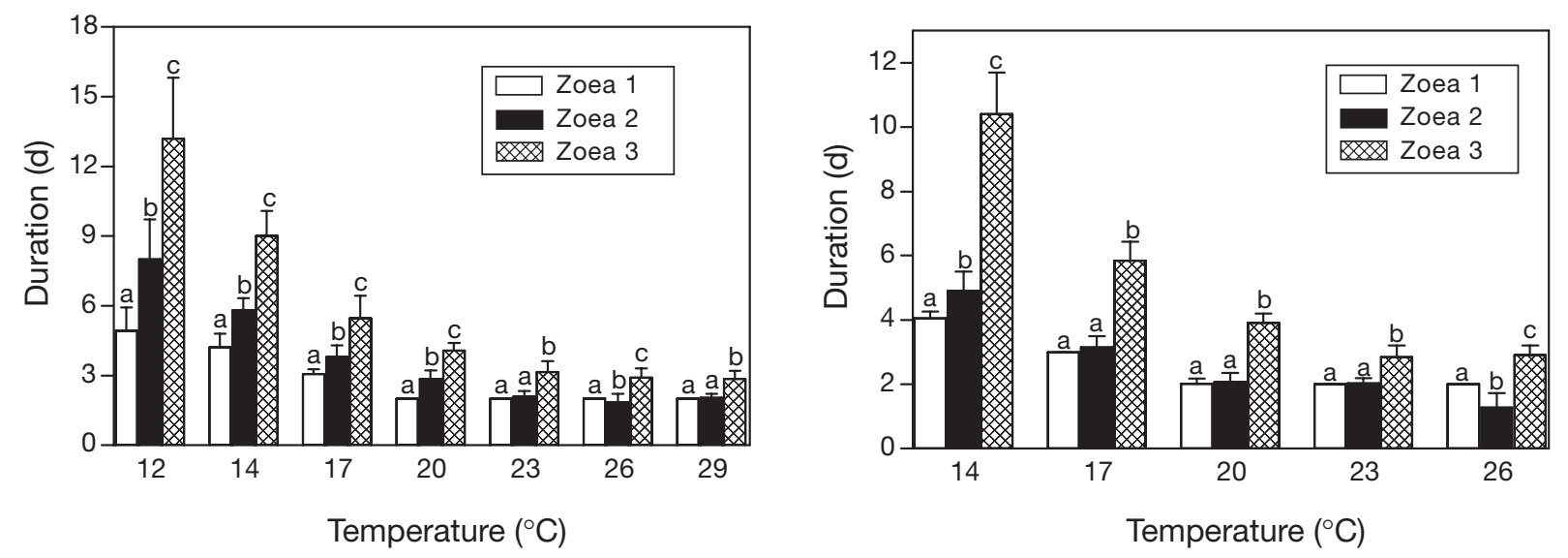

Fig. 5. Upogebia africana and U. capensis. Comparison of duration of development (mean \pm SD) of successive larval stages of U. africana (left) and U. capensis (right) at different constant temperatures. Statistics as in Fig. 3 (except that in all cases where letters are different $\mathrm{p}<0.01)$ 
Table 5. Upogebia capensis. Results of 1-way ANOVA comparing mean duration of development for successive zoeal stages and the cumulative larval period between temperatures (see also Fig. 5). Abbreviations as in Table 1

\begin{tabular}{|lccclrc|}
\hline Stage & dff & MSf & dfe & MSe & $F$ & $p$ \\
\hline Zoea 1 & 5 & 68.67 & 212 & 0.0179 & 3837.65 & $<0.001$ \\
Zoea 2 & 4 & 65.358 & 214 & 0.257 & 254.73 & $<0.001$ \\
Zoea 3 & 4 & 262.774 & 175 & 0.364 & 721.17 & $<0.001$ \\
Cumulative & 4 & 728.73 & 141 & 0.533 & 1367.47 & $<0.001$ \\
\hline
\end{tabular}

between 14 and $20^{\circ} \mathrm{C}$ were therefore subjected to regression analysis. Slopes of regressions for each stage differed significantly from one another (Zoea 1 versus Zoea 2: $F_{2,244}=19.117, \mathrm{p}<0.0001$; Zoea 1 versus Zoea 3: $F_{2,258}=97.417, \mathrm{p}<0.0001$; Zoea 2 versus Zoea 3: $\left.F_{2,232}=4.753, \mathrm{p}=0.03\right)$.

The trend in mean duration of development for successive zoeal stages of Upogebia capensis at each temperature differed to that for $U$. africana. Thus, while mean duration of development differed significantly between zoeal stages at the extreme temperatures where completed development was observed (14 and $26^{\circ} \mathrm{C}$ ), at $14^{\circ} \mathrm{C}$ the Zoea 1 had the shortest duration and the Zoea 3 the longest while at $26^{\circ} \mathrm{C}$ the Zoea 2 had the shortest duration (Table 6, Fig. 5). At the remaining temperatures (17, 20 and $23^{\circ} \mathrm{C}$ ), the Zoea 3 still had the longest mean duration of development but here the mean duration of development for the Zoea 1 was statistically similar to that for the Zoea 2.

Rates of development for the Zoea 1 of Upogebia africana and U. capensis at corresponding temperatures were almost identical (not significantly different, Table 7). The Zoea 2 of $U$. capensis usually completed development at significantly faster rates (exception was at $23^{\circ} \mathrm{C}$, where development rates were statistically similar), while the Zoea 3 of $U$. capensis completed development at significantly faster rates at 20 and $23^{\circ} \mathrm{C}$, at significantly slower rates at 14 and $17^{\circ} \mathrm{C}$, and at a similar rate at $26^{\circ} \mathrm{C}$ (Table 7 ). From a cumulative duration of development perspective, U. capensis larvae completed development at significantly faster rates compared with $U$. africana larvae at 20, 23 and $26^{\circ} \mathrm{C}$, development at 14 and $17^{\circ} \mathrm{C}$ proceeding at similar rates. It should be noted that, while the mean cumulative larval period at temperatures between 20 and $26^{\circ} \mathrm{C}$ was significantly different between the species, these differences amounted to less than half a day (see Figs. 5 \& 6).
Table 6. Upogebia capensis. Results of 1-way ANOVA comparing mean duration of development between zoeal stages at each rearing temperature (Temp., see also Fig. 5). Abbreviations as in Table 1

\begin{tabular}{|lccrrrc|}
\hline Temp. & dff & MSf & dfe & MSe & $F$ & $p$ \\
\hline $14^{\circ} \mathrm{C}$ & 2 & 120.864 & 109 & 0.447 & 270.52 & $<0.001$ \\
$17^{\circ} \mathrm{C}$ & 2 & 106.619 & 125 & 0.146 & 729.75 & $<0.001$ \\
$20^{\circ} \mathrm{C}$ & 2 & 40.818 & 108 & 0.0599 & 681.05 & $<0.001$ \\
$23^{\circ} \mathrm{C}$ & 2 & 6.778 & 101 & 0.0431 & 157.10 & $<0.001$ \\
$26^{\circ} \mathrm{C}$ & 2 & 17.19 & 91 & 0.0918 & 187.22 & $<0.001$ \\
\hline
\end{tabular}

\section{Fluctuating-temperature experiments}

Developmental stages

The predominant larval sequence in all treatments comprised 3 actively swimming zoeal stages followed by a metamorphic moult to the Decapodid. Intermediate larvae were encountered for Brood 1 larvae in Treatments 1 (4 ind.) and 2 (3 ind.), and for Brood 2 larvae in Treatments 1 (1 ind.) and 2 ( 2 ind.).
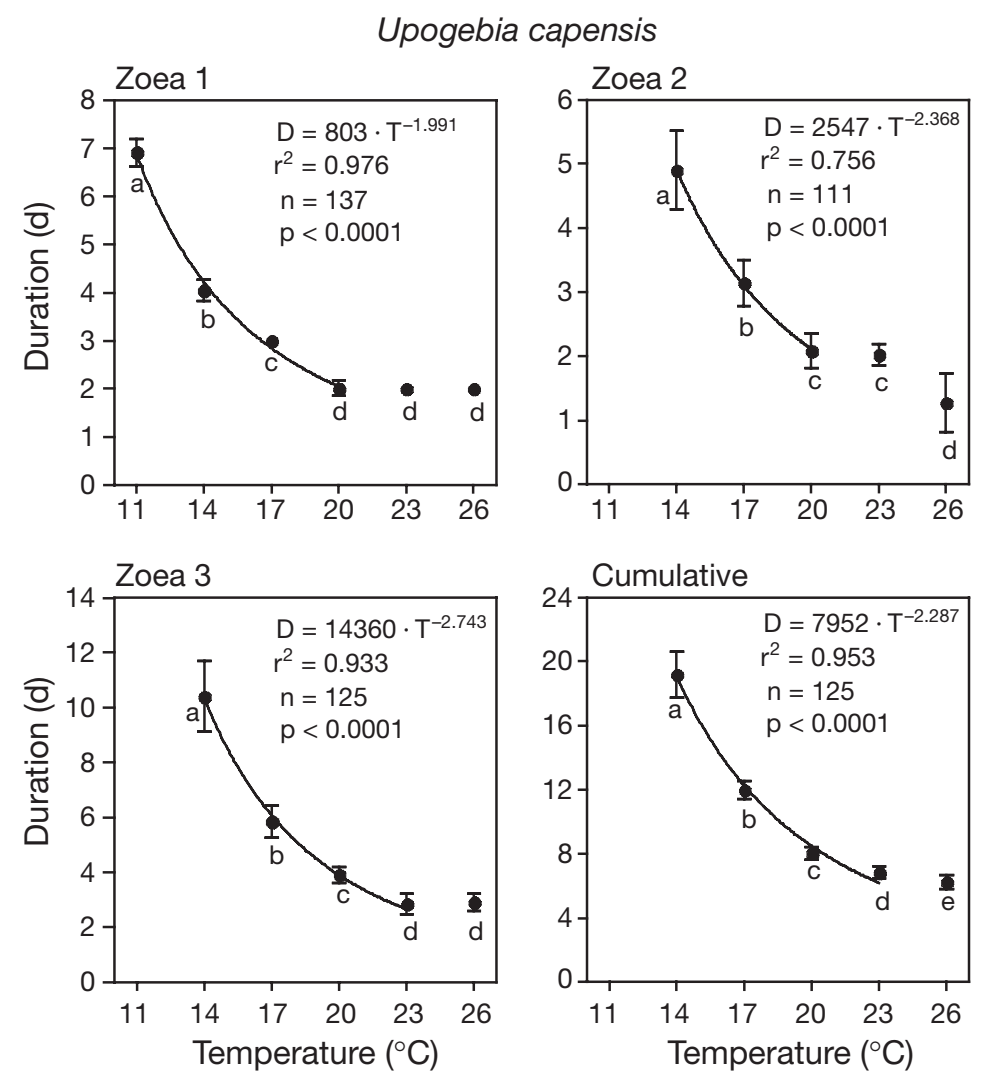

Fig. 6. Upogebia capensis. Effect of temperature $(T)$ on duration of development $(D$, mean $\pm \mathrm{SD})$ in successive larval stages and for cumulative larval development at temperatures less than or equal to threshold temperature (see text for further details). Statistics as in Fig. 4 
Table 7. Upogebia africana and U. capensis. Results of $t$-tests comparing mean duration of development of different zoeal stages between species at each rearing temperature. Ua: $U$. africana, Uc: $U$. capensis

\begin{tabular}{|c|c|c|c|c|c|}
\hline Stage & Temp. & $t$-value & $\mathrm{df}$ & $\mathrm{p}$ & Comparison \\
\hline \multirow[t]{5}{*}{ Zoea 1} & $14^{\circ} \mathrm{C}$ & 1.80 & 138 & 0.074 & $\mathrm{Ua}=\mathrm{UC}_{\mathrm{C}}$ \\
\hline & $17^{\circ} \mathrm{C}$ & 1.56 & 178 & 0.121 & $\mathrm{Ua}=\mathrm{UC}_{\mathrm{C}}$ \\
\hline & $20^{\circ} \mathrm{C}$ & 1.05 & 198 & 0.802 & $\mathrm{Ua}=\mathrm{Uc}_{\mathrm{c}}$ \\
\hline & $23^{\circ} \mathrm{C}$ & 0.00 & 205 & 1.000 & $\mathrm{Ua}=\mathrm{Uc}_{\mathrm{c}}$ \\
\hline & $26^{\circ} \mathrm{C}$ & 0.00 & 193 & 1.000 & $\mathrm{Ua}=\mathrm{Uc}$ \\
\hline \multirow[t]{5}{*}{ Zoea 2} & $14^{\circ} \mathrm{C}$ & 2.22 & 127 & 0.028 & $\mathrm{Uc}_{\mathrm{c}}<\mathrm{Ua}$ \\
\hline & $17^{\circ} \mathrm{C}$ & 8.10 & 176 & $<0.001$ & $\mathrm{Uc}_{\mathrm{c}}<\mathrm{Ua}$ \\
\hline & $20^{\circ} \mathrm{C}$ & 12.24 & 197 & $<0.001$ & $\mathrm{Uc}_{\mathrm{c}}<\mathrm{Ua}$ \\
\hline & $23^{\circ} \mathrm{C}$ & 1.11 & 201 & 0.268 & $\mathrm{Uc}_{\mathrm{c}}=\mathrm{Ua}$ \\
\hline & $26^{\circ} \mathrm{C}$ & 8.26 & 186 & $<0.001$ & $\mathrm{Uc}<\mathrm{Ua}$ \\
\hline \multirow[t]{5}{*}{ Zoea 3} & $14^{\circ} \mathrm{C}$ & 5.56 & 122 & $<0.001$ & $\mathrm{Uc}<\mathrm{Ua}$ \\
\hline & $17^{\circ} \mathrm{C}$ & 2.41 & 173 & 0.017 & $\mathrm{Uc}<\mathrm{Ua}$ \\
\hline & $20^{\circ} \mathrm{C}$ & 3.73 & 193 & $<0.001$ & $\mathrm{UC}_{\mathrm{C}}<\mathrm{Ua}$ \\
\hline & $23^{\circ} \mathrm{C}$ & 4.13 & 190 & $<0.001$ & $\mathrm{Uc}<\mathrm{Ua}$ \\
\hline & $26^{\circ} \mathrm{C}$ & 0.06 & 174 & 0.955 & $\mathrm{Uc}_{\mathrm{c}}=\mathrm{Ua}$ \\
\hline \multirow[t]{5}{*}{ Cumulative } & $14^{\circ} \mathrm{C}$ & 1.52 & 122 & 0.13 & $\mathrm{Uc}=\mathrm{Ua}$ \\
\hline & $17^{\circ} \mathrm{C}$ & 1.85 & 173 & 0.067 & $\mathrm{Uc}_{\mathrm{C}}=\mathrm{Ua}$ \\
\hline & $20^{\circ} \mathrm{C}$ & 10.94 & 193 & $<0.001$ & $\mathrm{Uc}<\mathrm{Ua}$ \\
\hline & $23^{\circ} \mathrm{C}$ & 4.19 & 190 & $<0.001$ & $\mathrm{Uc}<\mathrm{Ua}$ \\
\hline & $26^{\circ} \mathrm{C}$ & 4.67 & 174 & $<0.001$ & $\mathrm{Uc}<\mathrm{Ua}$ \\
\hline
\end{tabular}

\section{Survival}

Survival in both broods at the control temperature $\left(20^{\circ} \mathrm{C}\right)$ was high (Fig. 7) and not significantly different to that recorded at $20^{\circ} \mathrm{C}$ in the constant-temperature experiments ( $G$-tests for homogeneity, p > 0.05 in all cases). Stage-specific survival in Treatments 1 to 4 was not significantly different to that for the control temperature.

\section{Duration of development}

Mean duration of development for the Zoea 1 and Zoea 3 at the control temperature $\left(20^{\circ} \mathrm{C}\right)$ was statistically similar between the broods (Zoea 1: $t_{2,28}=0.00$, $\mathrm{p}=1.00$; Zoea $\left.3: t_{2,25}=0.90, \mathrm{p}=0.375\right)$, and for both broods also to the mean duration for these stages in the constant-temperature experiments at $20^{\circ} \mathrm{C}$ (Zoea 1: $F_{2,188}=1.00, \mathrm{p}=1.00 ;$ Zoea $3: F_{2,185}=2.80, \mathrm{p}=0.063$; Fig. 8). Zoea 2 larvae from Brood 2 developed at significantly faster rates compared with Brood 1 larvae $\left(t_{2,28}=2.646, \mathrm{p}=0.013\right)$, although rates of development for both broods were not significantly different to larvae in the constant-temperature experiments (1-way ANOVA, Tukey test comparisons with $\mathrm{p}=0.315$ for Brood 1 and $p=0.129$ for Brood 2). This difference in the duration of the Zoea 2, in combination with a slight (although not significant) delay in the Zoea 3 resulted



Brood 2
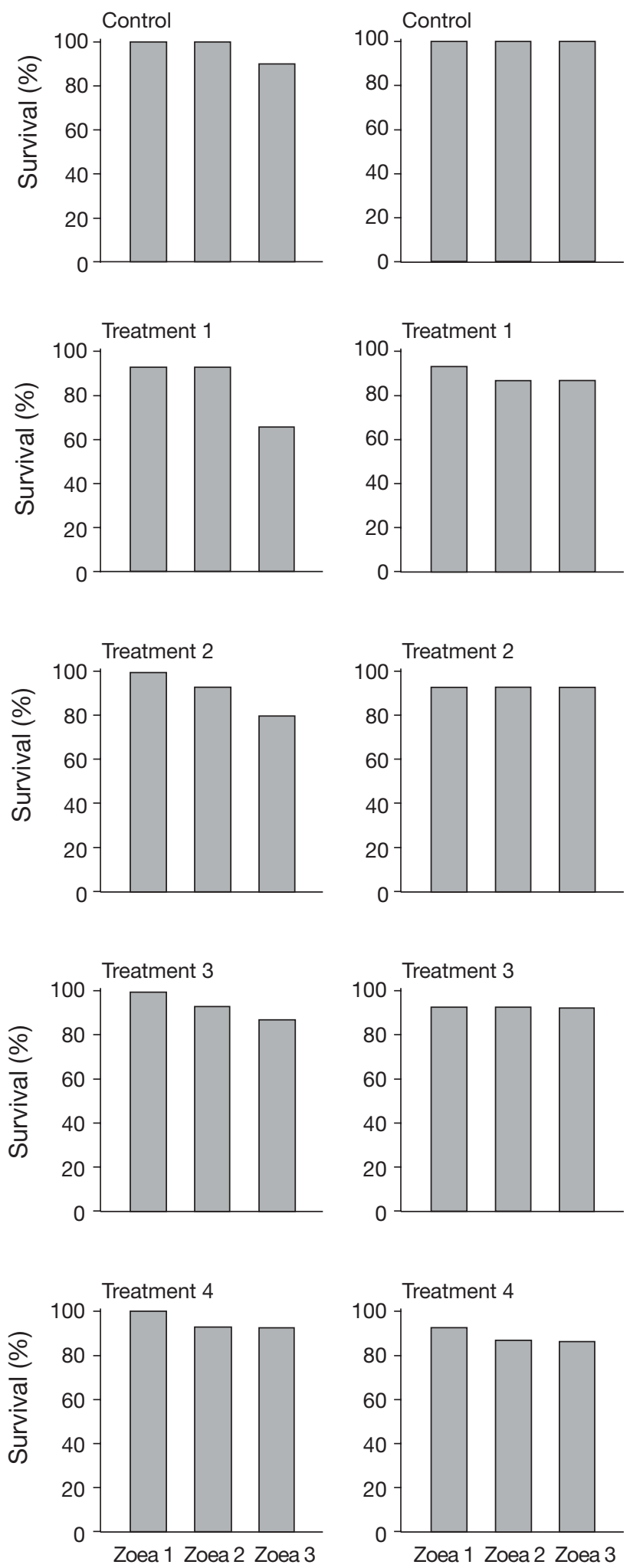

Fig. 7. Upogebia africana. Survival for Zoea 1 to 3 at $20^{\circ} \mathrm{C}$ (control) and in fluctuating-temperature treatments 
in the mean cumulative duration of development to the Decapodid for Brood 1 larvae being significantly longer compared with Brood 2 larvae $\left(t_{2,25}=2.44\right.$, $\mathrm{p}=0.022$; by about half a day), although cumulative duration of development for both broods was not significantly different to larvae in the constant-temperature experiments (1-way ANOVA, Tukey test comparisons with $\mathrm{p}=0.997$ and $\mathrm{p}=0.182$ respectively). Thus, despite the difference in development rates between the broods, larvae from each brood developed at statistically similar rates to larvae in the constant-temperature experiments, on which data regressions used to predict development periods under fluctuatingtemperature conditions were based.

Although a low proportion of larvae from Brood 1 metamorphosed to the Decapodid at the predicted time (8.6 d) in Treatment 1 (Fig. 9), most larvae completed development 1 to 2 d later, with a mean cumulative duration of development of $10.3 \pm 0.82 \mathrm{~d}$. In contrast, most larvae from Brood 2 completed development at or shortly after the predicted period, with a mean cumulative duration of development of $9.3 \pm$ $0.61 \mathrm{~d}$. Differences in the mean cumulative duration of development between the broods were significant $\left(t_{2,21}=3.28, \mathrm{p}=0.004\right)$. The predicted duration to the Decapodid in Treatment 2 was $9.3 \mathrm{~d}$. Larvae from Brood 1 completed development between 2 and $4 \mathrm{~d}$ later, with a mean cumulative duration of development of $12.1 \pm 0.84 \mathrm{~d}$. Most larvae from Brood 2 completed
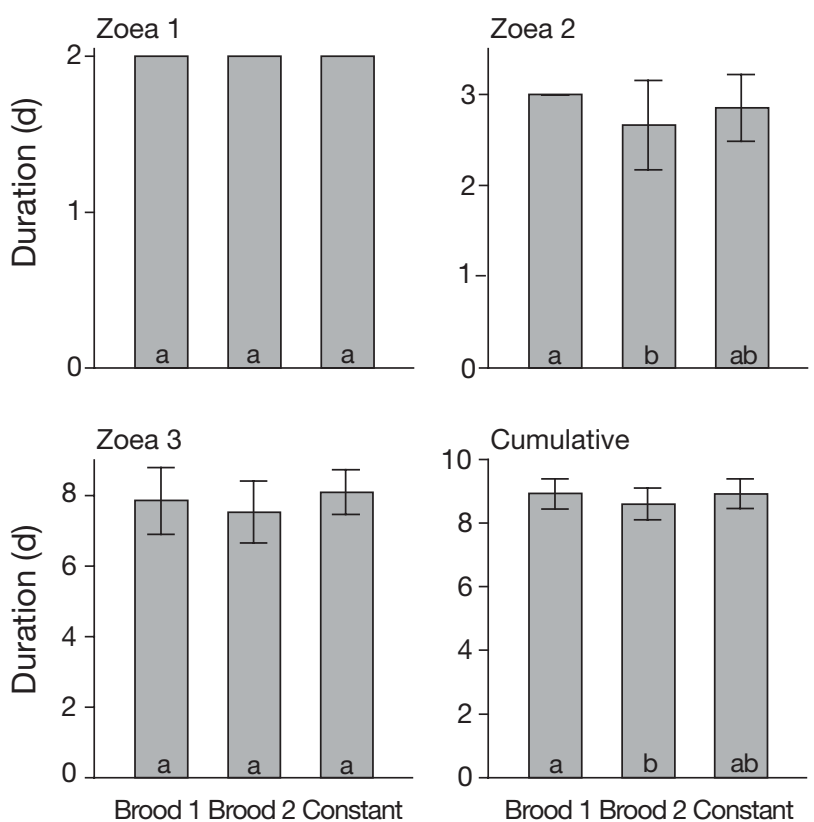

Fig. 8. Upogebia africana. Duration of development (mean \pm $\mathrm{SD}$ ) for Zoea 1 to 3 and cumulative larval development in Broods 1 and 2 at $20^{\circ} \mathrm{C}$ (control) and at $20^{\circ} \mathrm{C}$ in the constanttemperature experiments. Statistics as in Fig. 3 development at or $1 \mathrm{~d}$ after the predicted period, with a mean cumulative duration of $9.2 \pm 0.63 \mathrm{~d}$ (Fig. 9). Differences in the mean cumulative duration of development between the broods were significant $\left(t_{2,24}=\right.$ 10.14, p < 0.001).

The larval period in Treatment 3 was predicted at 11.5 and $11.2 \mathrm{~d}$ for Broods 1 and 2 respectively. The mean cumulative larval period for Brood 1 (12.08 \pm $0.28 \mathrm{~d})$ was slightly longer than the predicted period, while most larvae from Brood 2 completed development at the predicted time, with a mean cumulative larval period of $11.4 \pm 0.50 \mathrm{~d}$ (Fig. 9). In Treatment 4 the mean larval period for Brood $2(9.0 \pm 0.00 \mathrm{~d})$ was almost identical to the predicted period of $8.9 \mathrm{~d}$, development for Brood 1 larvae again delayed by about half a day $(10.0 \pm 0.56 \mathrm{~d}$ versus predicted period of $9.5 \mathrm{~d}$; Fig. 9).

\section{DISCUSSION}

\section{Constant-temperature experiments}

Although the thermal tolerance limits for Upogebia africana and $U$. capensis larvae were not defined in the present study, it is nevertheless apparent that larvae of both species are eurythermal; $U$. africana larvae were able to complete development to the Decapodid over a $17^{\circ} \mathrm{C}$ range, and $U$. capensis larvae over a $12^{\circ} \mathrm{C}$ range. Based on the survival for larvae of both species at the extreme temperatures examined (the exception was $U$. capensis at the lowest temperature examined, but see below for further discussion), there is reason to believe that larval tolerances to temperature may be greater. The present study evaluated the temperature responses of larvae hatched from females collected from only a single location (population), and there exists the possibility that acclimation of broods/ embryos, or collection of females/broods at disjunct locations within the distribution ranges of both prawns, could yield different temperature tolerances. Differences in the tolerance of larvae from spatially separated decapod populations to environmental parameters (e.g. temperature and salinity) is reported by several workers (see, for example, Laughlin \& French 1989), while other workers have reported the effects of exposure to these parameters during embryonic development on the tolerances of subsequent larval stages (non-genetic resistance adaptation, see Kinne 1971 p. 863-866; see, as examples, Charmantier et al. 2002, Giménez \& Anger 2003).

The wide tolerances to temperature and the temperature-mediated trends in the larval survival observed for both species in the present study are not only typical of decapods from temperate regions (for discussion, see 
Brood 1


Brood 2
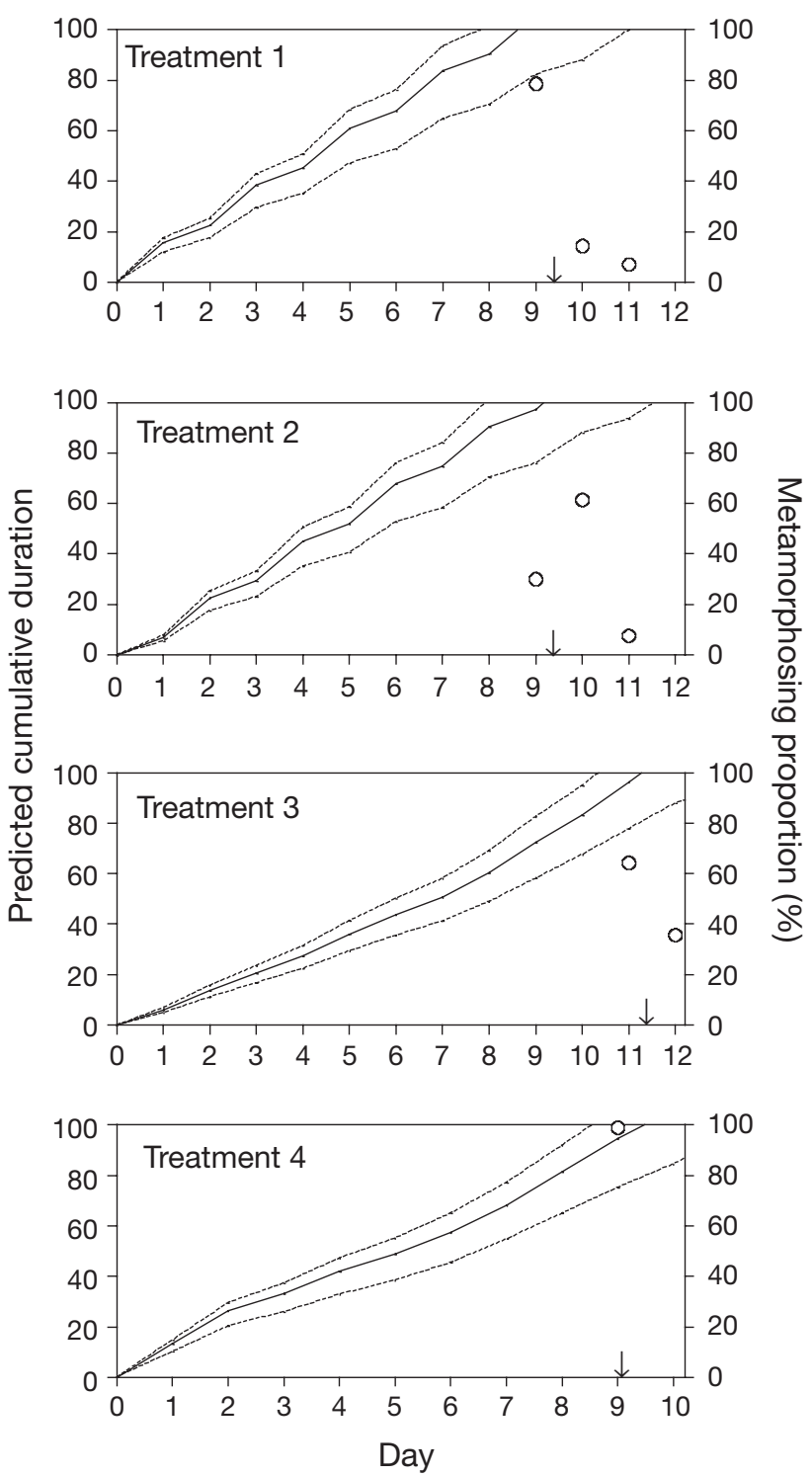

Fig. 9. Upogebia africana. Comparison of predicted and observed cumulative duration of development in fluctuating-temperature treatments. Predicted mean, minimum and maximum larval periods are presented as solid and dashed stepwise increases in development period, the 'steps' corresponding to the daily development rate. The position where the solid line intersects the upper limit of the graph indicates the predicted mean larval period, flanked on either side by predicted minimum and maximum periods (dashed lines). (O) Larval development periods observed in the laboratory, indicating the day(s) on which metamorphosis was observed. The height of the circles with reference to the right-hand axis denotes the proportion of larvae surviving to

Decapodid that metamorphosed on that day. Arrows indicate the mean duration of development to metamorphosis

Anger 2001) but also agree with the wide geographical ranges of adults of these species along the southern African coastline. The higher tolerance of $U$. africana larvae to warm temperatures compared with $U$. capensis larvae agrees with the further extension of the former species into warm subtropical waters along the east coast of southern Africa (Fig. 1). The high temperature tolerance of $U$. africana larvae also agrees well with the extended breeding period of this prawn in some parts of its range (up to 9 mo of the year; Hill 1967), the breeding period encompassing pronounced seasonal changes in water temperature. Although the inability of $U$. capensis larvae to complete development to the Decapodid at $11^{\circ} \mathrm{C}$ in the present study is surprising considering that the geographical range of this species extends far up the west coast of southern Africa, where the mean temperature of nearshore surface waters remains below $15^{\circ} \mathrm{C}$ for most of the year and decreases to as low as $9^{\circ} \mathrm{C}$ during 
summer upwelling events (South African Data Centre for Oceanography, data supplied to authors in nonreport format), larvae from only a single brood were reared at this temperature and further experimentation is necessary before the low-temperature response of the larvae can be defined with confidence. However, the apparent preference by $U$. capensis larvae for a temperature of $17^{\circ} \mathrm{C}$ is consistent with the restriction of this prawn to cooler waters along the southern and western coasts of southern Africa.

The west coast limit to the range of Upogebia africana ends abruptly at the Olifants River estuary (Fig. 1), but this appears to bear little relationship to the thermal tolerances of either larvae or adults. Adult $U$. africana are restricted to estuaries and sheltered embayments as a consequence of a requirement for a muddy substratum in which to construct burrows (Wooldridge 1968). Low rainfall and the consequent ephemeral nature of estuaries for a considerable distance to the north of the Olifants River estuary appears to provide an effective barrier to the northward expansion of the range of this prawn along the west coast.

Paula et al. (2001) examined the combined effects of temperature and salinity on the larval development of Upogebia africana in the laboratory. Since available data suggests overwhelmingly that $U$. africana larvae complete development in the marine environment (see Emmerson 1983, Wooldridge 1991, 1994, Wooldridge \& Loubser 1996), the influence of salinities below that of seawater on larval development was not considered in the present study. In Paula et al.'s (2001) experiments, development to the Decapodid (referred to by the latter authors as the megalopa) in seawater (35 ppt) was completed at 20 and $25^{\circ} \mathrm{C}$ only, all larvae reared at 15 and $35^{\circ} \mathrm{C}$ dying in the Zoea 1 and those reared at $30^{\circ} \mathrm{C}$ unable to complete the Zoea 3. Cumulative survival to the Decapodid at 20 and $25^{\circ} \mathrm{C}$ in Paula et al.'s (2001) study was considerably lower than that recorded at comparable temperatures in the present study, ranging between 5 and $25 \%$ compared with 76.8 and $83.4 \%$ respectively. Although the inability of larvae in Paula et al.'s (2001) experiments to complete development to the Decapodid at $15^{\circ} \mathrm{C}$ could possibly be explained by the fact that these workers collected ovigerous females from an estuary on the warm subtropical east coast of South Africa (Mgazana River estuary, Fig. 1), where the embryos would have been exposed to higher temperatures than those in the Swartkops River estuary, a similar reasoning cannot account for the very low cumulative survival at 20 and $25^{\circ} \mathrm{C}$, nor the inability of larvae to complete development at $30^{\circ} \mathrm{C}$, especially when it is considered that an average of $56.6 \%$ (range 33.3 to $80.0 \%$ ) of larvae in the present study completed development to the Decapodid at $29^{\circ} \mathrm{C}$. Although the reason for these differences must for the time being remain uncertain, the data of Paula et al. (2001) do not appear to provide a reliable indication of the temperature tolerance of $U$. africana larvae from the collection location (see also below).

In common with the larvae of other decapods (see, for example, Sulkin \& McKeen 1994, Anger 2001), Upogebia africana and $U$. capensis larval development rates were strongly influenced by temperature. Trends in mean duration of development as a function of temperature for each zoeal stage as well as the cumulative larval period was similar between the species. Thus, in both species stage-specific and cumulative duration of development decreased with increasing temperature until a threshold temperature, further increases in temperature having little additional influence on development rate. Development rates for the Zoea 1 were almost identical between the species, and although the mean duration of development for the Zoea 2 and 3 of $U$. capensis was usually significantly shorter compared with $U$. africana larvae at any temperature, in absolute terms these differences were small and usually amounted to less than half a day. In both species the Zoea 3 had the longest duration of development at each temperature, and its development thus comprised the largest proportion of the cumulative larval period. The Zoea 1 and 3 of $U$. capensis tended to comprise a slightly larger proportion of the cumulative larval period compared with $U$. africana, with the opposite for the Zoea 2.

The extent to which these similarities in the development rate of Upogebia africana and $U$. capensis larvae are the outcome of their close generic relationship and/ or are a consequence of similar evolutionary pressures facing the larvae is uncertain. As an example, while rapid development such as that observed in the Zoea 1 of both species may confer advantages such as limiting the length of time that larvae are exposed to predators in the water column (see, for example, Day \&McEdward 1984), such rapid development of this stage also appears to be a consequence of the fact that the Zoea 1 of both species is facultatively lecithotrophic, permitting its completion at a 'set' rate at any temperature irrespective of the availability of an external food source (Newman 2000).

The developmental periods recorded for Upogebia africana larvae in the present study are considerably shorter than those reported by Paula et al. (2001) at comparable temperatures and a salinity of $35 \mathrm{ppt}_{\text {; lar- }}$ vae reared at 20 and $25^{\circ} \mathrm{C}$ in the latter study had mean cumulative larval periods of about 19 and $13 \mathrm{~d}$ respectively, compared with $8.94 \pm 0.47$ and $6.69 \pm 0.49 \mathrm{~d}$ in the present study. The reason for this large (approximately 2-fold) discrepancy is uncertain, but as was the situation for the differences in survival between these populations it cannot adequately be explained by a latitudinal difference in water temperature. 


\section{Fluctuating-temperature experiments}

The effect of temperature fluctuations of the type simulated in the present study on Upogebia africana larval development was expressed principally through variations in the rate of development, survival generally little affected. Although cumulative survival in the fluctuating-temperature treatments was occasionally lower compared with the control temperature, these differences were not significant and showed no relationship to the temperature treatments per se, or to specific temperature fluctuations within these treatments. Even wide temperature fluctuations in experimental treatments (up to $8^{\circ} \mathrm{C}$ ) caused little mortality, suggesting that $U$. africana larvae are physiologically well adapted to survive wide, rapid fluctuations in water temperature in the natural environment. This has adaptive value, since upwelling is a common feature of the nearshore oceanography over large stretches of the geographical range of $U$. africana and can lead to wide, rapid decreases in water temperature of as much as $10^{\circ} \mathrm{C}$ within a few hours (Goschen \& Schumann 1995).

The primary objective for evaluating the influence of fluctuating temperature on Upogebia africana larval development was to determine whether regression models describing the influence of constant temperature on larval duration (first experiments) could be extrapolated to predict the larval period under fluctuating-temperature conditions typical of those in the natural environment. Although additional experimentation using larvae from more broods is necessary, based on the data generated it appears that extrapolation is reliable. In treatments that simulated temperature fluctuations typical of the natural environment (Treatments 3 and 4), most larvae completed development at or within a day (usually later) of the predicted period, while all larvae completed development within the predicted development period range. The largest discrepancies between predicted and observed larval periods occurred in Treatments 1 and 2, where larvae were exposed to wide $\left(8^{\circ} \mathrm{C}\right)$, cyclic fluctuations in temperature that are atypical of the natural environment. Here too, though, most larvae completed development within the predicted development period range. Although the delays in the mean development period in these treatments may seem inconsequential, they are highly significant when the short cumulative larval period of $U$. africana is taken into account, especially at high temperatures.

The temperature dependence of biological processes is well documented, and rates of metabolic processes in decapod larvae are undoubtedly reset on transfer from one temperature to another. However, this resetting (as measured through development rate) does not appear to be instantaneous, but to rather require a period of compensation, the extent of this compensatory period influenced by the previous exposure temperature and extent of temperature change. At the control temperature $\left(20^{\circ} \mathrm{C}\right)$, larvae from both broods completed the Zoea 1 after $2 \mathrm{~d}$, as would be predicted from the development data acquired at this temperature during the constant-temperature experiments. In Treatments 1 and 2, where the mean water temperature during the first $2 \mathrm{~d}$ of exposure was also $20^{\circ} \mathrm{C}$, the duration of the Zoea 1 could therefore also be predicted as $2 \mathrm{~d}$. However, with the exception of Brood 2 larvae in Treatment 1, larvae completed the Zoea 1 at rates significantly slower than those predicted (see Fig. 10). For both broods, exposure to $16^{\circ} \mathrm{C}$ on the first day (Treatment 2) significantly delayed development compared with exposure to $24^{\circ} \mathrm{C}$ on the first day (Treatment 1). These delays in development persisted to later larval stages, with the result that the mean cumulative larval period in Treatments 1 and 2 was also significantly prolonged compared with control larvae (Fig. 11). Upogebia africana larval development under fluctuating-temperature conditions is thus not simply additive of instantaneous rates of development at corresponding constant temperatures, the basic
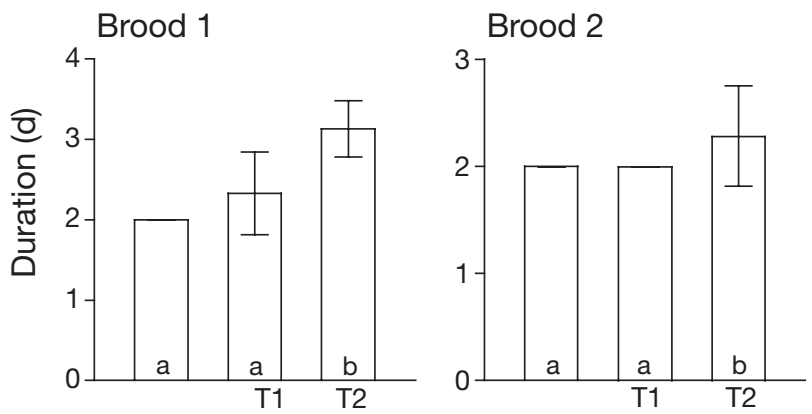

Fig. 10. Upogebia africana. Duration of development (mean \pm $\mathrm{SD}$ ) for the Zoea 1 in Broods 1 and 2 at $20^{\circ} \mathrm{C}$ (control) and Treatments 1 (T1) and 2 (T2). Statistics as in Fig. 3
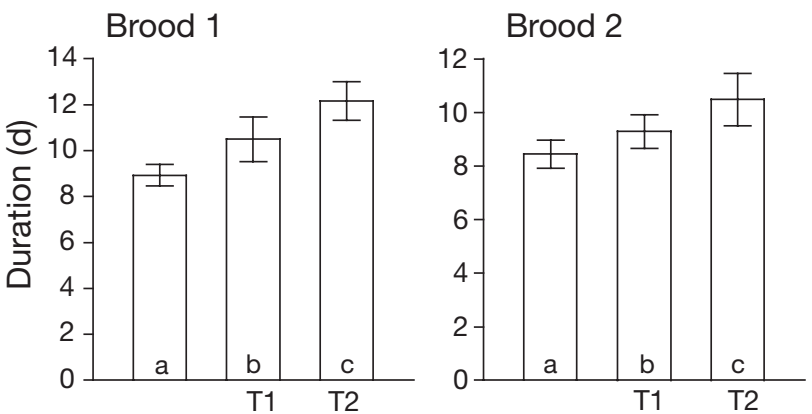

Fig. 11. Upogebia africana. Cumulative duration of development (mean $\pm \mathrm{SD}$ ) to the Decapodid in Broods 1 and 2 at $20^{\circ} \mathrm{C}$ (control) and Treatments 1 (T1) and 2 (T2). Statistics as in Fig. 3 
premise of the procedure used to predict larval period in this study. While the violation of this premise may account for discrepancies between observed and predicted larval periods in some treatments, at the same time it fails to account for strong similarities between predicted and observed periods in other treatments. Clearly there are additional issues that are important and which will require further evaluation before more concrete conclusions can be reached about the developmental responses of $U$. africana larvae to fluctuatingtemperature regimes.

Although the larval ontogeny of Upogebia africana incorporates 4 zoeal stages, only the first 3 stages are obligatory (Newman 2000). In that study the Zoea 4 was not detected in the constant-temperature experiments, but was detected in experiments examining the influence of starvation on $U$. africana larval development, where it was incorporated in the developmental sequence of a small proportion of larvae starved initially for $>48 \mathrm{~h}$ during the Zoea 1 and 2 . This prompted the hypothesis that nutritional stress was more important than temperature for inducing Zoea 3 larvae to moult to the Zoea 4 rather than undergo metamorphosis, but did not discount the possible influence of temperature fluctuations (Newmann 2000). Although factors inducing the Zoea 3 to moult to the Zoea 4 rather than to undergo metamorphosis are unresolved, data from the present study appear to discount the importance of upwelling-induced fluctuations in water temperature in this regard, provided that the larvae are well fed. Paula et al. (2001) detected the Zoea 4 in the laboratory during experiments examining the combined influence of salinity and temperature on $U$. africana larval development, suggesting that environmental parameters or interactions between parameters besides food availability may also be important in determining the developmental pathway followed.

Wide fluctuations in temperature per se do not appear to be important for inducing a moult to the intermediate stage in Upogebia africana, as illustrated by the absence of these larvae in Treatments 3 and 4 , where larvae were exposed to instantaneous 5 and $6^{\circ} \mathrm{C}$ fluctuations in temperature respectively. However, repeated wide fluctuations in water temperature, as simulated in Treatments 1 and 2, do appear to be important in inducing a moult to the intermediate stage at a higher frequency compared with constanttemperature conditions. Based on their morphology, intermediate larvae are almost certainly the expression of a disruption of endocrine control of the moult cycle. Repeated wide fluctuations in temperature may require such major and frequent resetting of temperature-controlled developmental processes that endocrine control of these processes is disrupted, pos- sibly through a lack of synchronicity between separately influenced yet linked and normally synchronised processes.

Acknowledgements. Financial support from the National Research Foundation and University of Port Elizabeth in the form of post-graduate bursaries (to B.K.N. and J.V.) and running costs is gratefully acknowledged. Five anonymous reviewers provided valuable comments on earlier drafts of this manuscript.

\section{LITERATURE CITED}

Anger K (1983) Temperature and the larval development of Hyas araneus L. (Decapoda: Majidae), extrapolation of laboratory data to field conditions. J Exp Mar Biol Ecol 69: 203-215

Anger K (2001) The biology of decapod crustacean larvae. In: Vonk R (ed) Crustacean issues, Vol 14. AA Balkema, Lisse

Barnard KH (1950) Descriptive catalogue of South African decapod crustacea. Ann Sth Afr Mus 38:1-836

Beckley L (1988) Spatial and temporal variability in sea temperature in Algoa Bay, South Africa. Sth Afr J Sci 84:67-69

Branch GM, Griffiths CL, Branch ML, Beckley LE (1994) Two oceans: a guide to the marine life of southern Africa. David Philip, Cape Town

Charmantier G, Giménez L, Charmantier-Daures M, Anger K (2002) Ontogeny of osmoregulation, physiological plasticity and larval export strategy in the grapsid crab Chasmagnathus granulata (Crustacea, Decapoda). Mar Ecol Prog Ser 229:185-194

Christensen MS (1980) Sea-surface temperature charts for Southern Africa, south of $26^{\circ} \mathrm{S}$. Sth Afr J Sci 76:541-546

Christiansen ME, Costlow JD (1975) The effect of salinity and cyclic temperature on larval development of the mud-crab Rhithropanopeus harrisii (Brachyura: Xanthidae) reared in the laboratory. Mar Biol 32:215-221

Dawirs RR (1985) Temperature and larval development of Carcinus maenas (Decapoda) in the laboratory, predictions of larval dynamics in the sea. Mar Ecol Prog Ser 24: 297-302

Day JH (1981) A guide to the marine life of South African shores. AA Balkema, Cape Town

Day R, McEdward L (1984) Aspects of the physiology and ecology of pelagic larvae of marine benthic invertebrates. In: Steidinger KA, Walker LM (eds) Marine plankton life cycle strategies. CRC Press, Boca Raton

Emmerson WD (1983) Tidal exchange of two decapod larvae Palaemon pacificus (Caridea) and Upogebia africana (Thalassinidae) between the Swartkops River estuary and adjacent coastal waters. Sth Afr J Zool 18:326-330

Felder DL, Martin W, Goy JW (1985) Patterns in early postlarval development of decapods. In: Wenner AM (ed) Crustacean issues, Vol 3. AA Balkema, Boston

Giménez L, Anger K (2003) Larval performance in an estuarine crab, Chasmagnathus granulata, is a consequence of both larval and embryonic experience. Mar Ecol Prog Ser 249:251-264

Goschen WS, Schumann EH (1995) Upwelling and the occurrence of cold water around Cape Recife, Algoa Bay, South Africa. Sth Afr J Sci 16:57-66

Hill BJ (1967) Contributions to the ecology of Upogebia africana (Ortmann). PhD thesis, Rhodes University, Grahamstown 
Hill BJ (1971) Osmoregulation by an estuarine and marine species of Upogebia (Anomura, Crustacea). Zool Afr 6: 229-236

Johnson DF, Hess KW (1990) Numerical simulations of blue crab larval dispersal and recruitment. Bull Mar Sci 46: 195-213

Kinne O (1971) Salinity - invertebrates In: Kinne O (ed) Marine ecology. A comprehensive integrated treatise on life in oceans and coastal waters. Vol 1, Environmental factors. Wiley Interscience, London, p. 821-995

Kaljeta B, Hockey PAR (1991) Distribution, abundance and productivity of benthic invertebrates at the Berg River estuary, South Africa. Est Coast Shelf Sci 33:175-191

Laughlin RB, French W (1989) Differences in responses to factorial combinations of temperature and salinity by zoeae from two geographically isolated populations of the mud crab Rhithropanopeus harrisii. Mar Biol 102: 387-395

Moloney CL, Botsford LW, Largier JL (1994) Development, survival and timing of metamorphosis of planktonic larvae in a variable environment: the Dungeness crab as an example. Mar Ecol Prog Ser 113:61-79

Newman BK (2000) Life-history strategies of the mudprawn, Upogebia africana Ortmann 1894 (Thalassinidea: Decapoda: Crustacea), during the marine phase of development. PhD thesis, University of Port Elizabeth

Paula J, Mendes RN, Paci S, McLaughlin P, Gherardi F, Emmerson W (2001) Combined effects of temperature and salinity on the larval development of the estuarine mud prawn Upogebia africana (Crustacea, Thalassinidea). Hydrobiologia 449:141-148

Rosenberg R, Costlow JD (1979) Delayed response to irreversible non-genetic adaptation to salinity in early development of the brachyuran crab Rhithropanopeus harrisii and some notes on adaptation to temperature. Ophelia 18: $97-112$

Editorial responsibility: Otto Kinne (Editor-in-Chief), Oldendorf/Luhe, Germany
Sastry AN (1979) Metabolic adaptations of Cancer irroratus developmental stages to cyclic temperatures. Mar Biol 51: 243-250

Schumann EH, Perrins LA, Hunter IT (1982) Upwelling along the south coast of the Cape Province, South Africa. Sth Afr J Sci 78:238-242

Schumann EH, Ross GJB, Goschen WS (1988) Cold water events in Algoa Bay and along the Cape south coast, South Africa, in March/April 1987. Sth Afr J Sci 84: 579-584

Sokal RR, Rohlf FJ (1981) Biometry. The principles and practice of statistics in biological research. WH Freeman and Co, San Francisco

Sulkin SD, McKeen GL (1994) Influence of temperature on larval development of four co-occurring species of the brachyuran genus Cancer. Mar Biol 118:593-600

Sulkin SD, McKeen GL (1996) Larval development of the mud crab Cancer magister in temperature regimes simulating outer-coast and inland water habitats. Mar Biol 127: 235-240

Wooldridge TH (1968) A study of the distribution of Upogebia africana (Ortm.) and Callianassa kraussi Stebb. in estuaries on the basis of substrate. BSc Hons thesis, Rhodes University, Grahamstown

Wooldridge TH (1991) Exchange of two species of decapod larvae across an estuarine mouth inlet and implications of anthropogenic changes in the frequency and duration of mouth closure. Sth Afr J Sci 87:519-525

Wooldridge TH (1994) The effect of periodic inlet closure on the estuarine mudprawn, Upogebia africana. Hydrobiologia 331:113-121

Wooldridge TH, Loubser H (1996) Larval release rhythms and tidal exchange in the estuarine mudprawn, Upogebia africana. Hydrobiologia 337:113-121

Zar J (1996) Biostatistical analysis. Prentice-Hall, Englewood Cliffs, NJ

Submitted: November 1, 2002; Accepted: February 20, 2006

Proofs received from author(s): October 13, 2006 